\title{
ARTERIAL STIFFNESS IS A RELEVANT MARKER OF CARDIOVASCULAR RISK
}

\author{
Belova N. \\ Department of Physiology, Medical University of Sofia, Bulgaria
}

\begin{abstract}
A b s tract
The cardiovascular diseases are still the leading cause of mortality and impaired quality of life worldwide. This fact implies the necessity of appropriate screening markers for focusing primary prevention on the individuals at higher cardiovascular risk.

The relevance of arterial stiffness as a predictor of future cardiovascular events is due to the fact it is a manifestation of the cumulative effect of all the harmful factors acting on the vascular wall, their duration and intensity, as well as of the genetic background of the individual.

The major structure of the vascular wall of the large "conduit" arteries is reviewed and the organization of the basic unit, the lamellar unit, is discussed in relation to the normal aging process and the concomitant alterations in arterial stiffness.

A review of the modern non-invasive methods for arterial stiffness evaluation is carried out: imaging of the relationship between vascular size and distending pressure; pulse wave analysis; measurement of pulse wave velocity (PWV).

A comparison of the resting brachial-ankle PWV (ba-PWV) is performed between two groups of young healthy adults: offspring of parents with cardiovascular pathology $(\mathrm{N}+)$ and their age matched controls $(\mathrm{N}-)$. Brachial-ankle PWV was significantly higher $(8.72 \pm 0.35 \mathrm{~m} / \mathrm{s})$ in $\mathrm{N}+$ as compared to $\mathrm{N}-(6.72 \pm 0.66 \mathrm{~m} / \mathrm{s})(\mathrm{P}<0.01)$. We consider the increased PWV as a consequence to an autonomic dysbalance and to an elevated sympathetic stimulation of the vascular smooth muscle in the healthy young adults with positive family history for cardiovascular pathology. We can conclude that measurement of ba-PWV is a relevant and cost-effective method for screening the individuals at higher cardiovascular risk.
\end{abstract}

Keywords: arterial stiffness; pulse wave velocity; cardiovascular risk; autonomic dysbalance.

\section{INTRODUCTION}

The cardiovascular diseases and their outcome are a major social burden. They are still the leading cause of morbidity and mortality worldwide. Hence, scientific research is directed towards the search for appropriate markers of individuals at higher cardiovascular risk in order to promote primary prevention.

The relevance of arterial stiffness as a predictor or marker of cardiovascular pathology has been definitely acknowledged by the recent Expert Consensus Document (1). In fact, the conduit and cushioning role (2) of large elastic arteries and the gradual impairment of the cushioning function with age has been demonstrated long ago. William Osler was the first to show that aging was frequently associated with arterial wall alterations, distinct from the localized and primarily intimal vascular lesions specific for atherosclerosis (3).

Typically for medical science, the "physiological" transformation of vascular wall was recently rediscovered and the introduction of sophisticated non-invasive diagnostic devices focused the attention of cardiologists on arterial stiffness. The functional consequence of aging per se is an increase in arterial stiffness, which results from the alterations and interactions between the extracellular matrix and the smooth muscle cells (SMC) of the media (4). Furthermore, the effects of aging are more pronounced in the proximal elastic arteries than in the more distal muscular arteries. "Physiological" aging affects to a greater extent the middle layer of the arterial wall, which is subjected to the continuous load of elastic

Address for correspondence:

Assoc. Prof. Nina Belova, MD, PhD, Department of Physiology, Medical University of Sofia, 1, G. Sofiiski Str., 1431 Sofia, Bulgaria

E-mail: belova.nina@gmail.com 
recoil. (5). However, hormonal, inflammatory and growth factors might modulate the effect of aging on vascular wall. For example, conditions like diabetes and renal dysfunction are frequently accompanied by earlier alterations in the large arteries, described as premature vascular aging (6).

In a brilliant way Nilsson and al. (7) gave ground for the significance of arterial stiffness as a cumulative measure of all negative factors, which had impacted the arterial wall, as opposed to the instantaneous condition shown by well-known markers as arterial pressure, metabolic parameters, which might be altered by random factors. In fact arterial stiffness reveals the specific long-term impact of various damaging factors, which depends both on the genetic background and on the diversity, the intensity and the duration of the harmful factor action on the arterial tree.

\section{FUNCTIONAL MORPHOLOGY OF TUNICA MEDIA IN THE LARGE ARTERIES}

Understanding the mechanisms of arterial wall remodeling necessitates a detailed knowledge of large artery structure and functions. The major structural elements of the vascular tunica media are smooth myocytes embedded in extracellular matrix. The basic unit of the media is the 'lamellar unit', which is composed of two elastic lamellae. The extracellular matrix of the media consists mainly of elastin and collagen fibers, microfibrils, and interlamellar ground substance containing glycosaminglycans and proteoglycans. This complex structure plays a role in vascular function both as a mechanical support and through biological signaling. The clarification of the interaction between SMC and matrix components may contribute to the development of new therapeutic approaches for the management of vascular pathology.

The viscoelastic properties of the arterial wall depend on the arrangement of the major structural components (8). Most lamellar units contain a single central layer of SMC, enveloped by a network of elastin protrusions (Fig. 1).

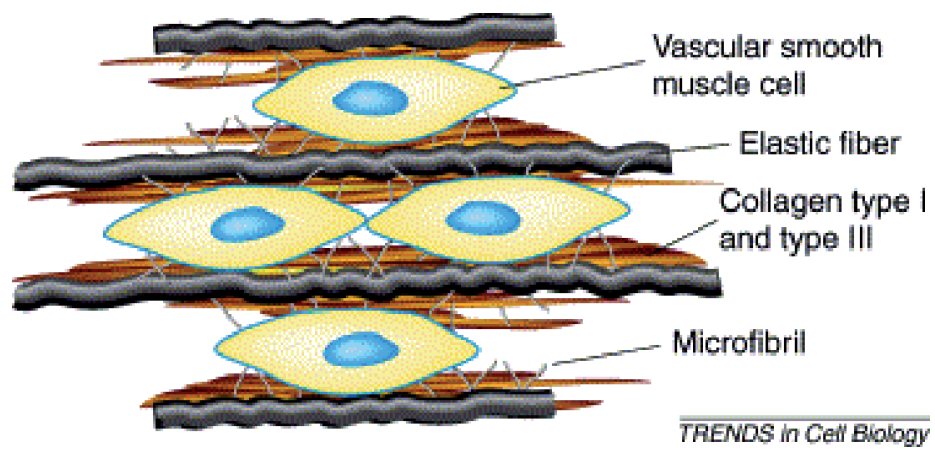

Fig. 1. The lamellar units consist of concentric layers of elastic lamellae, vascular smooth-muscle cells and interlamellar matrix. The extracellular-matrix components ensure the integrity of the arterial wall (Reproduced with the kind permission of DY Li (9).

The SMC are connected to the elastic protrusions with fibers build of the proteins fibrillin and type VI collagen. It has been shown that fibrillin stabilizes the interaction between SMC and the integrated matrix. Fibrillins bind to the integrins of SMC and this interaction is essential for the cell attachment and adhesion (9). In close proximity to the lamellae collagen fibrils form fibers, which are oriented in parallel to the lamellae. On the contrary, there is no specific orientation of the collagen fibrils in the central portion of the unit. (10).

Elastin is a protein of specific spring-like properties. This protein is the major factor contributing to the elasticity of conduit vessels, lungs and skin. Its elastic modulus is around 
$1 \mathrm{MPa}(11)$. What is more important, elastin is a protein of a very slow turnover - the halflife of elastin molecule is estimated to be more than 40 years. In addition, the synthesis of elastin is negligible in the adult individual (12). The elastin degradation rate depends on several factors: age, hormonal activity, stress, elastase activity, etc. (13)

The serine proteases and several matrix metalloproteinases (MMPs) possess the property to destroy elastin. The MMPs are a family of enzymes, which decompose extracellular matrix components and take part in morphogenesis and tissue remodeling. For example, the increased activity of MMP-9 and MMP-2 may cause destruction of the elastic lamellae and arterial remodeling (14).

Collagen is a comparatively inextensible protein (it might be stretched out to no more than $10 \%$ above its initial length), which confers firmness to the arterial wall. Collagen fibers are estimated to be 1000 times stiffer than elastin - collagen elastic modulus is around $1 \mathrm{GPa}$ (11). Yet, collagens are not only structural components; they are active participants of vascular extracellular matrix. They interact with many cell types within the arterial wall and these effects depend on the geometric organization of matrix microenvironment as well. Despite their strength, collagens are susceptible to proteolytic digestion and mineralization like elastin, which might contribute to arterial wall remodeling and stiffening (15). In their classic experiments Roach and Burton (16) showed the effect of trypsin digestion of elastin or formic acid degradation of collagen on the tension-length curves of the iliac arteries. They were the first to evidence the non-linearity of arterial wall elasticity. The increased stiffness of arterial wall at larger distention of the vessel was attributed to the tensed collagen fibers. Aortic collagen fibers are assembled in bundles and no specific arrangement of those bundles is observed at low pressures. However, at higher than physiological pressures the collagen fibers in the media align circumferentially and they are the main contributors to the increased stiffness of the wall under these conditions (17).

The elastin/collagen ratio is highest in the large conduit arteries. It gradually decreases with the concomitant increase in SMC number per unit of mass and the decrease of arterial lumen in muscle arteries. Recent experiments using elastase-treated arteries demonstrated the significance of elastin-collagen interdependence. Elastin destruction led to collagen fiber recruitment and non-linearly increased arterial stiffness, especially in conditions of elevated circumferential stress (18).

\section{ARTERIAL STIFFNESS}

Arterial stiffness is a property of the vascular wall, which is hard to be defined and even more difficult to be precisely measured. Arnett and al. defined arterial stiffness as an estimate of the ability of large arteries to expand in response to the systolic ejection of stroke volume (19). Arterial stiffness is inversely proportional to arterial distensibility and arterial compliance (20). In fact the terms stiffness, compliance and elasticity are a manifestation of volume changes in the vessel in response to a pressure change, while distensibility depends on the initial vascular dimensions as well (21).

Further on, Greenwald (12) differentiates the terms material stiffness and functional stiffness. Material stiffness of the arterial wall is manifested by its resistance to distension in response to an applied force and, therefore, it is related to its structural components. Yet, Greenwald introduces the term functional stiffness, which is the apparent stiffness of the vascular wall. The apparent stiffness depends on the ratio thickness/lumen of the vessel as well. The functional consequence is that an artery of a thicker wall would show greater functional stiffness than a vessel with similar structural characteristics but of a thinner wall. Theoretically, this also means that functional stiffness will depend on smooth muscle tone, which determines vascular diameter. A constricted vessel would have a smaller thickness/lumen ratio and its functional stiffness should be greater and vice versa.

Therefore, in short-term conditions the contractile function of smooth muscle cells (SMCs) contributes to the arterial mechanical properties. The pattern of SMC arrangement is dif- 
ferent in the large arteries as compared to SMC architecture in the more distal muscular arteries. In the conduit arteries the myocytes bridge the elastic lamellae, while in the muscular arteries they form rings parallel to the elastic lamellae. This arrangement pattern in the large arteries determines the specific contribution of SMC contraction to arterial wall stiffness $(22,23,24)$. On the contrary to resistance vessels, the relatively small amount of $\mathrm{SMC}$ in the elastic arteries determines a small diameter reduction upon contraction. Hence, the functional effect of SMC contraction is a redistribution of force between the collagen and elastin fibers, i.e. modulation of tension. This might explain the existence of acute arterial stiffness dynamics $(25,26)$.

It also should be kept in mind that arterial stiffness is a function of the distending pressure as already discussed due to the recruitment of collagen fibers; hence, arterial stiffness should be considered a dynamic property of the vessel (27).

All these assumptions give theoretical reasons for expecting a reduction in arterial stiffness through appropriate interference with SMC contraction.

\section{EFFECT OF AGING ON LARGE ARTERIAL CHARACTERISTICS}

The long-term gradual stiffening of the elastic arteries might be related to changes in the composition, altered geometry and the resulting redistribution of forces within the arterial wall. The large arteries dilate, they get more rigid and their wall thickens $(28,29)$.

The structural alterations in the media components act not only as a causative agent for a change in material stiffness; they lead to altered cell-matrix interactions as well (30). There are a lot of putative mechanisms for intracellular signalling in the genesis of arterial stiffness, which could be therapeutically targeted only after understanding the underlying mechanisms.

The typical changes in vascular media with aging are summarized by Lakatta et al. as elevated collagen/elastin ratio, increased amount of matrix, matrix metalloproteinase (MMP) dysregulation and increased number of SMC (31).

The gradual decrease in elastin content is a physiological manifestation of aging. Aging is accompanied not only by loss of elastic fibers, but also by thinning, splitting and fragmentation of elastin $(32,33)$. This phenomenon was described by O'Rourke as elastin fatigue (34). The elastin lamellae progressively thin, and, in addition, they are put under an increased wall tension according to Laplace's law due to arterial dilation accompanying aging. Therefore, the aortic elastin reduction accounts for the decreased aortic compliance $(35,36)$.

In addition, it should be pointed out that elastin has a high affinity for calcium, and agerelated elastic fiber fragmentation is associated with a greater predisposition for calcification. Besides, it has been shown that MMP mediated elastin degradation leads to formation of soluble elastin peptides, which also may induce calcium deposition. Elastin calcification was associated with an up-regulation of the MMP mRNA expression, MMP-9 and MMP-2, in particular (37).

Those unfavorable changes in extracellular matrix (ECM) proteins are promoted and accelerated by inflammation and immunological stress, in which condition inflammatory cells produce increased amounts of MMPs and elastase (38).

Several studies suggest that genetic factors might influence at least in part the elastic properties of large arteries. A positive association between gene polymorphism of angiotensin II receptor type $1\left(\mathrm{AT}_{1}{ }^{1166} \mathrm{~A} / \mathrm{C}\right)$ and of aldosterone synthase $\left(\mathrm{CYP} 11 \mathrm{~B}_{2}{ }^{344} \mathrm{~T} / \mathrm{C}\right)$ with aortic stiffness has been shown in hypertensive subjects $(39,40)$. A significant decrease in carotid artery distensibility was observed in individuals carrying Ser422Gly polymorphism in the gene-encoding elastin. The interesting point was that the association of elastin gene polymorphism and increased stiffness existed only in subjects above 50 years, which implies the existence of an age-genotype interaction (41).

Fibrillin-1 genetic polymorphism was also associated with large artery stiffening and increased cardiovascular risk (4). 
It has also been shown that MMP-3 gene polymorphism could lead either to increased production of the enzyme with the ensuing arterial wall weakness and risk of aneurysm formation, or to increased extracellular matrix deposition because of decreased levels of MMP3 . The optimal intermediate levels of the enzyme leading to a balance between matrix deposition and breakdown are observed in individuals with heterozygous MMP-3 expression (42). On the contrary, MMP-9 gene polymorphism with elevated levels of the enzyme in the aorta was related to elastic matrix degradation and remodeling, which causes arterial stiffening (43).

\section{EVALUATION OF ARTERIAL STIFFNESS} (44):

In general, three approaches might be used to measure non-invasively arterial stiffness

1. Assessment of the relationship between vessel size and distending pressure usually by means of echo-tracking techniques, aplanation tonometry and magnetic resonance imaging;

2. Pulse wave analysis with the help of aplanation tonometry or echo-tracking, which provides data about the alterations in the aortic pulse wave contour;

3. The gold standard for arterial stiffness assessment is the measurement of pulse wave velocity (PWV). This method is based on the equation of Moens-Korteweg: $\mathrm{PWV}^{2}=\mathrm{Eh} / 2 \mathrm{r} \rho$, where E is Young's modulus (estimated by the slope of the stress-strain relationship of the vessel); $\rho$ is blood density, $h$ is vascular wall thickness and $r$ is vascular radius. PWV in the central arteries increases with age and what is more important - it increases non-linearly and of a higher rate above the age of 50 (45).

\section{ASSESSMENT OF ARTERIAL STIFFNESS BY MEASUREMENT OF BRACHIALANKLE PULSE WAVE VELOCITY (BA-PWV)}

Recently there are several papers, which give evidence for a good correlation between aortic or central PWV and the brachial-ankle PWV (ba-PWV), which is easier for estimation $(46,47)$.

We have measured ba-PWV to compare arterial stiffness in two groups of normotensive young adults: young individuals with family history for increased cardiovascular risk $(\mathrm{N}+)$ as compared to their age matched controls $(\mathrm{N}-)$. The $(\mathrm{N}+)$ individuals were the offspring of parents and/or grand parents with hypertension, diabetes, obesity and/or target organ damage like myocardial infarction or brain stroke. Their general characteristics are shown on Table 1 .

Table 1. General characteristics of the studied individuals.

Data are means \pm SEM. HR - Heart rate at rest $\left(\mathrm{min}^{-1}\right)$; SAP - Systolic arterial pressure at rest (mm Hg); PP - Pulse pressure at rest (mm Hg).

\begin{tabular}{|c|c|c|c|c|c|c|}
\hline Groups & $\mathbf{n}$ & Age & BMI & HR & SAP & PP \\
\hline $\mathbf{N}+$ & 35 & $20.4 \pm 0.4$ & $23.3 \pm 0.6$ & $75 \pm 1.3$ & $119 \pm 1.6$ & $43 \pm 1.3$ \\
\hline $\mathbf{N}-$ & 9 & $21.5 \pm 0.8$ & $22.2 \pm 0.5$ & $69 \pm 3$ & $113 \pm 4$ & $39 \pm 2$ \\
\hline
\end{tabular}

As it is clearly seen from Table 1 the studied subjects were age matched, non-obese and normotensive. There were slight differences in the resting heart rate, systolic arterial pressure and pulse pressure. All these parameters were within the normal range, although higher in the $\mathrm{N}^{+}$group. Yet, no statistical significance could be shown. 
The measurement of ba-PWV was carried out in supine position of the patient after 10 min for adaptation and taking the baseline brachial arterial pressure. Two photoplethysmograms (PPG) were simultaneously recorded from the right a. brachialis and the right a. dorsalis pedis using the Biopac MP 100 digitizer and the Acknowledge software.

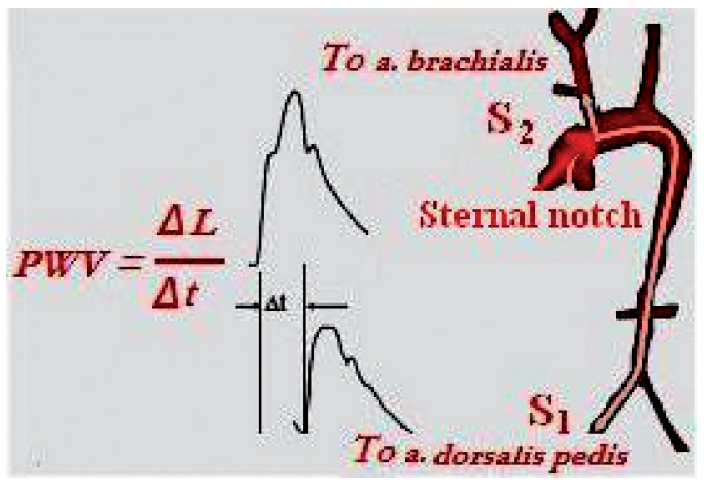

Fig. 2. The route difference traveled by the pulse wave corresponds to the time lag between the foot of the brachial and dorsal pedis photoplethysmograms. $\mathrm{S}_{2}$ corresponds to the shorter distance traveled by the pulse wave between the sternal notch and the brachial artery recording site; $\mathrm{S}_{1}$ is the longer distance between the sternal notch and the dorsal pedis recording site.
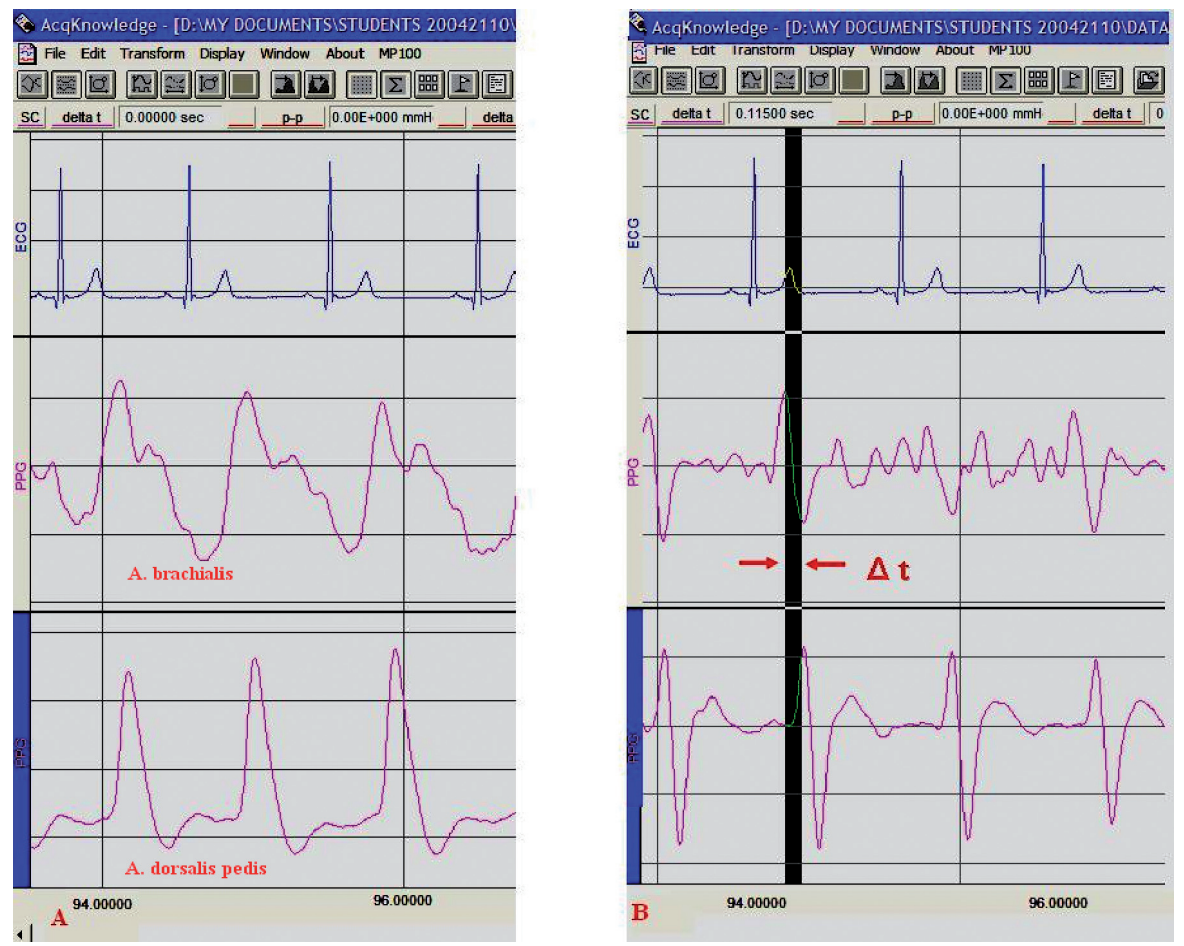

Fig. 3. Two screens from the AcqKnowledge software. A. Simultaneous recording of electrocardiogram and two photoplethysmograms from a. brachialis and a. dorsalis pedis. B. Calculation of the time lag between two fiducial corresponding points of the photoplethysmograms: the onset of the anacrotic phase. It is measured as the time interval between the respective peaks of the photoplethysmogram second derivatives. 
PWV calculation was based on the difference in the route traveled by the pulse wave (Fig. 2 ) to the sites of recording (brachial artery and dorsal pedis artery) and on the time lag $(\Delta t)$ between the start of the anacrotic phase in the respective PPG (Fig. 3). Hence, ba-PWV = $\Delta \mathrm{L} / \Delta \mathrm{t}$.

A screen from the software program AcqKnowledge with a simultaneous recording of the two PPG is shown on Fig. 3A. Figure 3B demonstrates the calculation of the time lag between the two fiducial corresponding points of the PPGs. It is measured as the time interval between the peaks of the second derivatives of the PPG curves, which peaks coincide with the opening of the aortic valve and the transition to the ascending phase of the curve (48). The corresponding route is calculated as follows. The route traveled by the pulse wave from the aortic semilunar valve to the branching of the truncus brachiocephalicus dexter (positioned roughly beneath the sternal notch) is common for both distances. The shorter route $\mathrm{S}_{2}$ is measured from the sternal notch to the brachial artery recording site. The greater distance $S_{1}$ to the dorsal pedis site is calculated using the formula $S_{1}=(0.8129 x$ height $+12.328) / 100$, where $S_{1}$ is in $\mathrm{m}$ and height is in cm. Hence, $\Delta \mathrm{L}=\mathrm{S}_{1}-\mathrm{S}_{2}(46)$.

Our ba-PWV data correspond to the reference values given by Boutouyrie et al. (49) for central PWV. Yet, we have shown the existence of a significantly higher ba-PWV in the N+ individuals as compared to the controls $(\mathrm{P}<0.01$, Fig. 4). The resting value in $\mathrm{N}$ - it was 6.72 $\pm 0.66 \mathrm{~m} / \mathrm{s}$, while in $\mathrm{N}+$ it was $8.72 \pm 0.35 \mathrm{~m} / \mathrm{s}$.

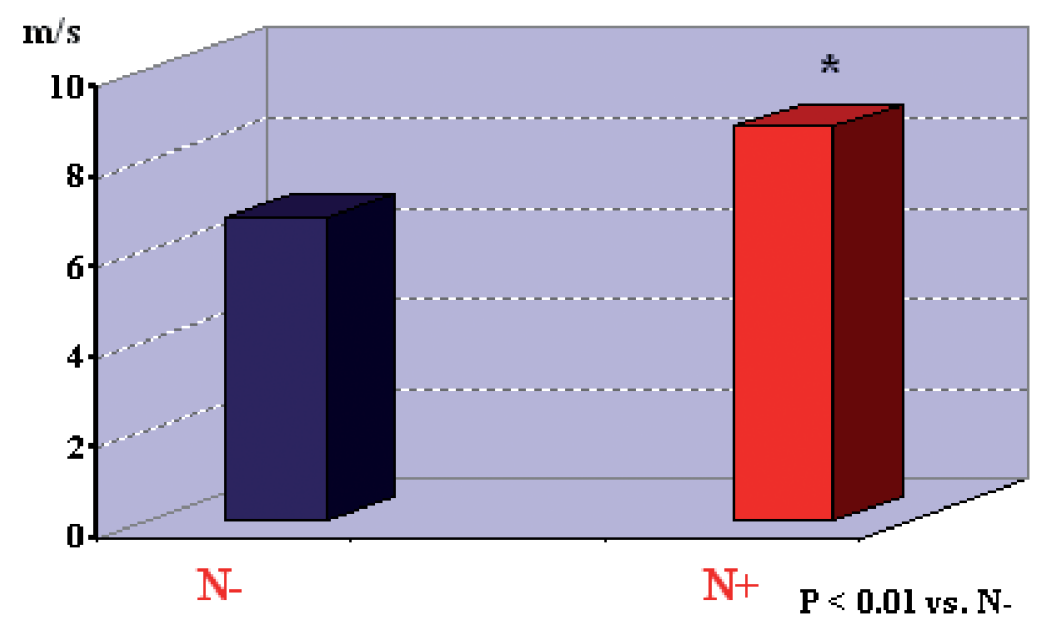

Fig. 4. Brachial-ankle PWV is significantly higher in the $\mathrm{N}+$ individuals as compared to the control group.

We plan to carry out additional studies that could clarify the cause(s) for the higher PWV in the individuals with positive family history for increased cardiovascular risk.

The putative underlying mechanisms comprise genetic factors that could determine a premature morphological "aging" of the arterial wall. There are studies showing the existence of gene polymorphisms associated with variance in the arterial stiffness phenotype. These studies are elegantly presented in the review of Lacolley and al. (50). Several candidate gene polymorphisms are discussed in this review: renin-angiotensin-aldosterone genes, matrix and metalloproteinase genes, endothelial cell related genes, inflammatory genes, etc. Yet, the average age of the studied individuals in the above cited genome linkage studies is more advanced than in our subjects: it is higher than 40. This fact is not surprising as the accumulation of influences on a composite parameter such as the arterial stiffness needs more time to produce a manifested alteration. 
So, interpreting our results we are inclined to speculate that the higher PWV in the young, healthy and normotensive individuals with positive family history for cardiovascular risk could be associated with functional rather than structural causes. As it has been already shown the change in the vascular smooth muscle tone due to sympathetic stimulation might cause increased arterial wall rigidity $(25,51,52,53)$. Our hypothesis is that an autonomic dysbalance with a sympathetic predominance exists in those individuals. This idea is supported by earlier studies of ours showing the existence of altered heart rate variability in similar groups of subjects (54). Although not statistically significant, the slightly higher resting heart rate, systolic pressure and pulse pressure in the $\mathrm{N}+$ are also in favor of the existence of elevated sympathetic drive to the cardiovascular system.

In conclusion, the measurement of ba-PWV is an easy for performance, non-invasive and cost-effective method that might be used as an additional tool in a battery of functional tests for screening individuals at higher cardiovascular risk.

\section{REFERENCES}

1. Laurent S, Cockcroft J, Van Bortel L, Boutouyrie P, Giannattasio C, Hayoz D et al. Expert consensus document on arterial stiffness: methodological issues and clinical applications. Eur Heart J 2006; 27: 2588-2608.

2. O'Rourke M. Arterial aging: pathophysiological principles. Vascular Medicine 2007; 12 : 329-341.

3. Osler W. The principles and practice of medicine. Appleton, $3^{\text {rd }}$ edition, 1898.

4. Kingwell BA, Medley TL, Waddell TK, Cole TJ, Dart AM, Jennings GL. Large artery stiffness: structural and genetic aspects. Clin Exper Pharmacol Physiol 2001; 28: 1040-1043.

5. O’Rourke M, Mancia G. Arterial stiffness. J Hypertens 1999; 17: 1-4.

6. McEniery CM, Wilkinson IB, Avolio AP. Age, hypertension and arterial function, Clinical and Experimental Pharmacology and Physiology 2007; 34: 665-671.

7. Nilsson PM, Boutouyrie P, Laurent S. A Tale of EVA and ADAM in Cardiovascular Risk Assessment and Prevention, Hypertension 2009; 54: 3-10.

8. Wolinsky H, Glagov S. A lamellar unit of aortic medial structure and function in mammals. Circ Res 1967; 20: 99-111.

9. Brooke BS, Karnik SK, Li DY. Extracellular matrix in vascular morphogenesis and disease: structure versus signal. Trends in Cell Biology 2003; 13 (1): 51-56.

10. Dingemans KP, Teeling P, Lagendijk JH, Becker AE. Extracellular matrix of the human aortic media: An ultrastructural histochemical and immunohistochemical study of the adult aortic media. Anat Rec 2000; 258: $1-14$.

11. Shadwick RA. Mechanical design in arteries, J Exper Biol 1999; 202: 3305-3313.

12. Greenwald SE. Ageing of the conduit arteries. J Pathol 2007; 211(2): 157-172.

13. Wilkinson IB, McEniery CM, Cockcroft JR. Arteriosclerosis and Atherosclerosis: Guilty by Association. Hypertension 2009; 54:1213-1215.

14. Sharon Wallace Y, McEniery CM, Dakham Z, Pusalkar P, Maki-Petaja K, Ashby MJ, Cockcroft JR, Wilkinson IB. Matrix Metalloproteinase-9 (MMP-9), MMP-2, and Serum Elastase Activity Are Associated With Systolic Hypertension and Arterial Stiffness. Arterioscler Thromb Vasc Biol 2005; 25: 372-378.

15. Adiguzel E, Ahmad PJ, Franco C, Bendeck MP. Collagens in the progression and complications of atherosclerosis. Vasc Med 2009; 14: 73-89.

16. Roach MR, Burton AC. The reason for the shape of the distensibility curves of arteries. Can J Biochem Physiol 1957; 35(8): 681-690.

17. Faury G. Function-structure relationship of elastic arteries in evolution: from microfibrils to elastin and elastic fibres. Pathol Biol 2001; 49: 310-25.

18. Fonck E, Prod'hom G, Roy S, Augsburger L, Rüfenacht DA, Stergiopulos N. Effect of elastin degradation on carotid wall mechanics as assessed by a constituent-based biomechanical model, Am J Physiol Heart Circ Physiol 2007; 292: H2754-H2763.

19. Arnett DK, Evans GW, Riley WA. Arterial Stiffness: A New Cardiovascular Risk Factor? Amer J Epidemiol 1994; 140: 669-682.

20. Van Bortel LM, Kool MJ, Struijker Boudier HA. Effects of Antihypertensive Agents on Local Arterial Distensibility and Compliance. Hypertension 1995; 26: 531-534.

21. Cohn JN, Quyyumi AA, Hollenberg NK, Jamerson KA. Surrogate Markers for Cardiovascular Disease: Functional Markers. Circulation 2004;109: IV-31-IV-46.

22. Dobrin PB. Mechanical properties of arteries, Physiol Rev 1978; 58: 397-460.

23. Bank AJ, Wang H, Holte JE, Mullen K, Shammas R, Kubo SH. Contribution of collagen, elastin, and smooth muscle to in vivo human brachial artery wall stress and elastic modulus. Circulation 1996; 94(12): 3263-70. 
24. Zulliger MA, Rachev A, Stergiopulos N. A constitutive formulation of arterial mechanics including. Am J Physiol Heart Circ Physiol 2004; 287: H1335-H1343.

25. Rachev A, Hayashi K. Theoretical study of the effects of vascular smooth muscle contraction on strain and stress distributions in arteries. Ann Biomed Eng 1999; 27: 459-468.

26. Oliver JJ. Webb DJ. Noninvasive assessment of arterial stiffness and risk of atherosclerotic events. Atheroscler Thromb Vasc Biol 2003; 23: 554-566.

27. Van Bortel LM, Duprez D, Starmans-Kool MJ, Safar ME, Giannattasio C, Cockcroft J, Kaiser DR, Thuillez C, Clinical applications of arterial stiffness, Task Force III: recommendations for user procedures. Am J Hypertens 2002; 15(5): 445-452.

28. O'Rourke MF, Hashimoto J. Mechanical Factors in Arterial Aging A clinical perspective. J Am Coll Cardiol 2007; 50: $1-13$.

29. Hashimoto J, Ito S. Some mechanical aspects of arterial aging: physiological overview based on pulse wave analysis. Ther Adv Cardiovasc Dis 2009; 3: 367-378.

30. Durier S, Fassot C, Laurent S, Boutouyrie P, Couetil JP, Fine E, Lacolley P, Dzau VJ, Pratt RE. Physiological genomics of human arteries: quantitative relationship between gene expression and arterial stiffness. Circulation. 2003; 108(15): 1845-1851.

31. Najjar SS, Scuteri A, Lakatta EG. Arterial Aging, Is It an Immutable Cardiovascular Risk Factor? Hypertension 2005; 46: 454-462.

32. Lakatta EG, Mitchell JH, Pomerance A, Rowe GG. Human aging: changes in structure and function. J Am Coll Cardiol 1987; 10: 42A-47A.

33. Pezet M, Mariko B, Jacob MP, Faury G.. Les fibres elastiques: un regulateur du vieillissement normal ou pathologique des vaisseaux sanguins elastiques. Medecine \& Longevite 2009; 1: 64-75.

34. O’Rourke M. Arterial aging: pathophysiological principles. Vascular Medicine 2007; 12: 329-341.

35. Avolio A, Jones D, Tafazzoli-Shadpour M. Quantification of Alterations in Structure and Function of Elastin in the Arterial Media. Hypertension 1998; 32:170-175.

36. Cheng KS, Baker CR, Hamilton G, Hoeks APG, Seifalian AM. Arterial Elastic Properties and Cardiovascular

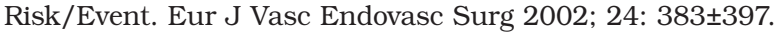

37. Atkinson J. Aging of arterial extracellular matrix elastin: etiology and consequences. Pathol Biol (Paris) 1998; 46(7): 555-559.

38. Shirwany NA, Zou M. Arterial stiffness: a brief review. Acta Pharmacologica Sinica 2010; 31: 1267-1276.

39. Benetos A, Gautier S, Ricard S, Topouchian J, Asmar R, Poirier O, Larosa E, Guize L, Safar M, Soubrier F, Cambien F. Influence of angiotensin-converting enzyme and angiotensin II type 1 receptor gene polymorphisms on aortic stiffness in normotensive and hypertensive patients. Circulation 1996; 94: 698-703.

40. Pojoga L, Poirier O, Guyen TT, Gautier S, Cambien F, Benetos A. Genetic determination of plasma aldosterone levels in essential hypertension. Am J Hypertens 1998; 11: 856-860.

41. Hanon O, Luong V, Mourad JJ, Bortolotto LA, Jeunemaitre X, Girerd X. Aging, Carotid Artery Distensibility, and the Ser422Gly Elastin Gene Polymorphism in Humans. Hypertension 2001; 38: 1185-1189.

42. Medley TL, Kingwell BA, Gatzka CD, Pillay P, Cole TJ. Matrix Metalloproteinase-3 Genotype Contributes to AgeRelated Aortic Stiffening Through Modulation of Gene and Protein Expression. Circulation Research 2003; 92: 1254-1261.

43. Medley TL, Cole TJ, Dart AM, Gatzka CD, Kingwell BA. Matrix Metalloproteinase-9 Genotype Influences Large Artery Stiffness Through Effects on Aortic Gene and Protein Expression. Arteriosclerosis, Thrombosis, and Vascular Biology 2004; 24: 1479-1484.

44. Sakuragi S, Abhayaratna WP. Arterial stiffness: Methods of measurement, physiologic determinants and prediction of cardiovascular outcomes. International Journal of Cardiology 2010; 138: 112-118.

45. McEniery CM, Yasmin, Hall IR, Gasem A, Wilkinson IB, Cockcroft JR. Normal vascular aging: differential effects on wave reflection and aortic pulse wave velocity: the Anglo-Cardiff Collaborative Trial (ACCT). J Am Coll Cardiol 2005; 46(9): 1753-1760.

46. Yamashina A, Tomiyama H, Takeda K, Tsuda H, Arai T, Hirose K, Koji Y, Hori S, Yamamoto Y. Validity, Reproducibility, and Clinical Significance of Noninvasive Brachial-Ankle Pulse Wave Velocity Measurement. Hypertens Res 2002; 25 (3): 359-364.

47. Sugawara J, Hayashi K, Yokoi T, Cortez-Cooper MY, DeVan AE, Anton MA, Tanaka H. Brachial-ankle pulse wave velocity: an index of central arterial stiffness? J Hum Hypertens 2005; 19(5): 401-406.

48. Millasseau SC, Ritter JM, Takazawab K, Chowienczyk PJ. Contour analysis of the photoplethysmographic pulse measured at the finger. J Hyperten 2006; 24: 1449-1456.

49. Boutouyrie P, Vermeersch SJ. Determinants of pulse wave velocity in healthy people and in the presence of cardiovascular risk factors: 'establishing normal and reference values'. The Reference Values for Arterial Stiffness' Collaboration. European Heart Journal 2010; 31: 2338-2350.

50. Lacolley P, Challande P, Osborne-Pellegrin M, Regnault V. Genetics and pathophysiology of arterial stiffness. Cardiovasc Res 2009; 81: 637-648.

51. Mangoni A, Mircoli L, Giannattasio C, Mancia G, Ferrari A. Effect of sympathectomy on mechanical properties of common carotid and femoral arteries. Hypertension 1997; 30:1085-1088.

52. Failla M, Grappiolo A, Emanuelli G, Vitale G, Fraschini N, Bigoni M Grieco NA, Denti M, Giannattasio C, Mancia G. Sympathetic tone restrains arterial distensibility of healthy and atherosclerotic subjects. J Hypertens 1999; 17:1117-1123. 
53. Orr JS, Dengo AL, Rivero JM, Davy KP. Arterial Destiffening With Atorvastatin in Overweight and Obese Middle-Aged and Older Adults. Hypertension 2009; 54: 763-768.

54. Belova NY, Mihaylov SV, Piryova BG. Wavelet transform: A better approach for the evaluation of instantaneous changes in heart rate variability. Autonom Neurosci: Basic and Clin 2007; 131: 107-122.

Acknowledgments: This study was supported by Grant DO 02-26/2009 of the Bulgarian Fund for Scientific Research and by Grant SK-BG 0009-08.

Received: May, 2, 2011

Accepted: July, 17, 2011 